\title{
"The Desire of the Rose": Tattooing, Ekphrasis, and Queer Desire in Texts by Samuel Steward and Sylvia Plath
} \author{
Sylvia Plath \\ Louisa Söllner \\ Catholic University of Eichstätt-Ingolstadt \\ louisa.Soellner@ku.de
}

"El deseo de la rosa": tatuaje, écfrasis y deseo queer en textos de Samuel Steward y

\section{Resumen}

Este ensayo explora los textos de Samuel Steward y Sylvia Plath que interactúan con el espacio cultural del estudio de tatuajes. El artículo se centra en la narración de Plath “The Fifteen Dollar Eagle" y en las múltiples narraciones de Steward sobre su transformación de profesor universitario a artista tatuador. Mis lecturas trazan la manera en que un conflicto con los patrimonios literarios del modernismo, surgidos a través de la marginación del deseo queer en las tradiciones modernistas, lleva a ambos autores a inclinarse por espacios culturales alternativos. En sus textos, el tatuaje no solo crea inscripciones epidérmicas, sino que también promete una subversión de las jerarquías sociales y estéticas y permite imaginar relaciones que desafían la heteronormatividad.

Palabras clave: tatuajes, écfrasis, deseo queer, Samuel Steward, Sylvia Plath

\begin{abstract}
This paper explores texts by Samuel Steward and Sylvia Plath that engage with the cultural space of the tattoo studio. It focuses on Plath's story “The Fifteen Dollar Eagle" and on Steward's various narratives about his transformation from a university professor into a tattoo artist. My readings trace how a conflict with the literary heritages of modernism, emerging through the marginalization of queer desire in modernist traditions, leads both authors to turn to alternative cultural spaces. Tattooing, in their texts, not only produces epidermal inscriptions, but also promises a subversion of social and aesthetic hierarchies and permits imagining relationships that defy heteronormativity.
\end{abstract}

Keywords: tattoos, ekphrasis, queer desire, Samuel Steward, Sylvia Path

Fecha de recepción: 26 de noviembre de 2018 | Fecha de aceptación: 13 de marzo de 2019 


\section{Challenging Modernist Ideals: Tattooing and Queer Desire}

he increasing popularity of tattooing as a "cultural, artistic, and social form" (DeMello 2) demands a reconsideration of the aesthetic traditions that have shaped our understanding of tattooing as an art. This paper focuses on the role of tattooing and queer desire in North American literature that emerged in or explores cultural environments of the 1950 os and the following decades. In what follows, I offer a comparative reading of texts by Samuel Steward and Sylvia Plath. The dialogue between Steward, a university professor who reinvented himself as a tattoo artist and writer of gay pornography in the $1950 \mathrm{os},{ }^{1}$ and Plath, whose oeuvre tends to be overshadowed by her suicide in 1963 and is persistently read with a focus on confessional or autobiographical elements, ${ }^{2}$ may appear far-fetched at first glance. In what follows, I suggest, however, that tattooing appealed to both writers for similar reasons and that Plath and Steward both turned to this particular art form because it promised a liberation from repressive aesthetic ideals and allowed them to imagine a sphere in which writing could embrace queer desire. While homosexuality became a vital element of Steward's self-reinvention in the 1960, after his turn from academia, Plath merely seems to toy with the idea of lesbianism in her writing. ${ }^{3}$ I suggest that the references to same-sex desire scattered across her various prose pieces are a means of expressing unease with the social norms that determined the understanding of gender and sexuality in the 1950's. Similar to her fascination with tattooing, these references are gestures of dissociation from heteronormative relationships, and from the modernist aesthetic ideals that shaped Plath's cultural and intellectual environment.

Before I delve into the exploration of Steward's and of Plath's writing, I wish to offer some preliminary ideas about the role of queer desire and tattooing in the

${ }^{1}$ For more information, see Justin Spring. Secret Historian. The life and times of Samuel Steward, professor, tattoo artist, and sexual renegade (2010).

${ }^{2}$ Tracy Brain in The Other Sylvia Plath (2001) offers a revisionist account that rejects the persistent focus on autobiographical elements in the earlier commentaries, and instead pays closer attention to the style and politics of Plath's writing.

${ }^{3}$ Julia Gordon-Bramer points out: "While Plath was heterosexual, she pondered in writing about lesbians and the lifestyle“ (198). 
framework of modernist aesthetics. Heather Love argues in Feeling Backward that literary modernism is characterized by a "temporal splitting": the desire for novelty that seems vital to modernist literature belies the intimate association of many of these texts with "backwardness," the "nonmodern," the primitive, the traditional, or the melancholic (6). While modernist literature is a gesture into the future, it is also marked by an interest in spheres that seem incompatible with narratives of progress. Love characterizes same-sex desire as a sentiment that resists the wish to look forward and is therefore "branded as nonmodern" (7). Love's observations are interesting in this context, as they show that aesthetics are not a sphere that remains dislodged from ideology. Instead, she depicts modernist art as one of the domains in which heteronormative ideals manifest themselves.

Love's thoughts also help to clarify the marginalized status of tattooing in modernist art. Hans Georg von Arburg speculates that, with the rise of primitivism in the 1920s, tattooing could have become an important reference medium in visual art and literature, in his essay "Archäodermatologie der Moderne" (438). Tattooing connotes pain, the permanent inscription of the human body, and visual immediacy. These qualities certainly turn the medium into a potential source of inspiration for modernist writing. There are, however, only few modernist texts that make overt references to tattooing. Love's observations offer one possible explanation for this omission: The narrative about modernist art she constructs suggests that, similar to queer desire, tattooing was a cultural practice that remained incompatible with the greater narrative of progress that influenced modernist art and shaped its desire for novelty. These observations show that, while there are no vital connections between tattooing and queer desire, both are pushed into peripheral positions in modernist aesthetics, due to their ability to disturb the capitalist logic of progress.

Both Steward and Plath probe new trajectories in their writing and position themselves at some remove from literary modernism. How can the fascination with tattooing their oeuvres be framed methodologically? Karin Beeler, in her monograph Tattoos, Desire and Violence, helpfully points out that references to tattooing in literary texts should be understood as ekphrastic descriptions (3). She also suggests that ekphrastic literature that evolves around tattooing often poses "resistance to hegemony" (5). Theorizations of ekphrasis frequently accentuate the risks that literary engagements with the visual entail: the translation of an image 
into words, inevitably, sheds light on the limitation of language because words are not endowed with the "capaciousness" or "immediacy" of pictures, even if writers seek to equip them with these qualities (Krieger 5). Ekphrasis is thus concerned with comparing media and feeds on impulses of appropriation and competition. One problem with the scholarship on ekphrasis is that it often employs a heteronormative framework in order to explain the relationship between different media. James Heffernan postulates that the competition between image and text "is often powerfully gendered" and fantasizes about "the voice of male speech striving to control a female image that is both alluring and threatening" (1). More recent approaches seek to remedy this understanding of ekphrasis. Brian Glavey, writing from a perspective of queer studies, notes that the ekphrastic impulse to imitate other art forms also offers interesting possibilities to writers who are concerned with homosexual experience because it permits to transfigure stigma into aesthetic value and can inspire a "reevaluation of the experience of being treated as an image or a copy" $(7)$. This observation is interesting for my project about tattooing and queer desire, as it affirms that queer ekphrasis questions ideologically charged aesthetic values such as authenticity or originality. Tattooing, as an art form, is similarly prone to defy aesthetic hierarchies and thus potentially able to enhance the effects of queer ekphrasis. In what follows, I flesh out the idea that Steward's and Plath's texts challenge modernist aesthetics and examine repressive sexual norms by turning to tattooing as a reference medium.

\section{Samuel Steward: From the Avant-garde to the Tattoo Studio}

"Was tattooing not the farthest distance I could get from the academic world?" (Bad Boys and Tough Tattoos 12) - Samuel Steward offers this rhetorical question as a response to inquiries on why he abandoned his academic career in order to become a tattoo artist. Steward had gained a PhD at Ohio State University in 1934 and published his first novel, Angels on the Bough, in 1936. After his graduation, he taught at various colleges and universities, among them Loyola University and DePaul University in Chicago. From the early 1930s onwards, he cultivated a 
correspondence with Gertrude Stein, which led to a friendship that lasted until Stein's death in 1946. In spite of the modest success of his novel and his ongoing identification as a writer, Steward never published any other works of fiction that would have fit into a modernist canon. Instead, he penned pornographic fiction, known as the "Phil Andros stories," in the decades after his turn from academia, and dabbled in a variety of other genres, including autobiographical accounts a series of crime novels that evolve around Stein and Toklas as investigators.

In 1990, Steward also published a book about his experiences as a tattoo artist. The volume is based on notes he had collected for Alfred Kinsey as a foundation for research about the "sexual motivations for getting tattooed" (3) and appeared under the title Bad Boys and Tough Tattoos: A Social History of the Tattoo with Gangs, Sailors and Street-Corner Punks, 1950-1965. While the classification of the text as a "social history" suggests a scholarly approach, this impression is revoked by Steward's choice to list the members of his cast in the subtitle: the promise of "gangs, sailors and street-corner punks" announces an inclination to the anecdotal, which turns out to be programmatic. In his introduction to the volume, Steward remarks that "the chronological formula" he uses in the first chapters of the volume, give it the appearance of an "autobiography" and explicitly asks his readers not to "expect the arrangement and symmetry of the scholar's monograph" (3-4).

Steward's choice of tattooing over teaching, of the "skidrow of South Street in Chicago" over the academic establishment, of "the chaos of life" over "logic, order, and design," and of image over word, responds to Beeler's association of "tattoo texts" with "resistance to hegemony" (5). Scholarship on ekphrasis traditionally discusses literary texts that describe works of fine art; the focus on tattooing Beeler selects is a novel approach. The affiliation of tattooing with the imperfect, scarred body and with desires Beeler describes as "messy" (191) adds new risks -as well as new temptations and new pleasures- to the encounter between literary texts and the visual. One of these risks is breaking away from "high art" and entering the realms of subculture. Steward's description of his turn away from literature and academia towards tattooing embodies this dimension: "I was sliding down into a world of which I knew absolutely nothing. The life ahead of me was as different from the life I had known as benedictine is from cheap red wine" (12). Steward enters a new cultural position, a position that, from the vantage point of academia remains obscure, perhaps invis- 
ible, but which also offers new possibilities of self-invention. He, for instance, notes that many of the anecdotes about tattooing he presents in his book "would seem misplaced or frivolous in a scholarly work" -"sliding down" thus permits him to explore forms of expression that are usually excluded from academic writing.

However, the new cultural position Steward occupies, after becoming a tattoo artist also threatens his connection to the "inner circles" of the literary avant-garde (13). A conflict between his ongoing intellectual and artistic identifications and his occupation as a tattooist and author of queer pornography becomes tangible through obsessive references to Gertrude Stein and Alice B. Toklas in Steward's oeuvre. Steward, for instance, explains the non-academic, anecdotal approach in Bad Boys and Tough Tattoos with the following words: "Alice B. Toklas once suggested that I should let the 'weight of the anecdotes carry the thing.' I have tried to do this" (4). This remark appears incongruous in the context of a work about tattoo culture. Steward's allusion to Toklas and Stein's mentorship thus reads as an attempt to forge links to the modernist traditions from which tattooing dissociates him.

He performs a comparable gesture in an introductory "Note" to his collection of pornographic prose pieces Below the Belt (1982). The collection was published under the name of the narrator and protagonist of the stories, Phil Andros. Steward explains his relationship with Phil through a Stein reference: "like Gertrude Stein speaking to Alice about her biography - I said to him that I was going to write the stories, and I did, and here's a dozen of them" (x). The emulation of Stein's writing in a book of pornographic fiction allows for various interpretations. It insinuates that, in spite of his rejection of aesthetic hierarchies, Steward is unable to let go of the fantasy of belonging to the "inner circles" of the avant-garde and that he still cultivates the desire for a literary genealogy that leads back to modernism. At the same time, we can also understand the reference to Stein as a gesture of disidentification by which Steward seeks to salvage Stein's lines from canonization and from reading practices that drain them of their provocative potential and queer subtext. ${ }^{4}$

${ }^{4}$ José Esteban Muñoz conceptualizes disidentification as a "strategy that tries to transform a cultural logic from within" (11); Steward's engagement with Stein similarly seems to oscillate between identification and the desire to change the reception of her work. See: Disidentifications: Queers of Color and the Performance of Politics (1999). 
He rewrites Stein's words and places them in a context in which homosexual desire is openly expressed.

The tension between Steward's ongoing identification as an intellectual and his urge to resist heteronormative ideologies is also negotiated in the story "Love me little, love me long," that appeared in Below the Belt. The text envisions erotic encounters between the young hustler Phil Andros and the aging tattooist Pete Swallow. Both men navigate cultural territories that seem incongruous with their highbrow tastes. Phil begins his narrative with the following sentence: "I wandered lonely as a cloud on South State Street in Chicago" (36). The apparent mismatch between the Wordsworth citation and the rundown Chicago neighborhood is emblematic for Phil's ability to shuttle between different domains of identification. Pete similarly defies easy categorization: "What the hell was an intellectual doing in a tattoo shop?" (38).

At one point in the story, Phil acquires a tattoo that resembles one of Steward's tattoos. He is thus marked as an idealized alter ego of Steward. Similarly, Pete Swallow figures as an impersonation of Steward, who used the "pen name" Phil Sparrow for his work as a tattoo artist. In light of this doubling, it is not surprising that both men discover parallels in their biographies, such as mutual ex-lovers (42). The analogies motivate them to conceptualize their relationship in terms of kinship and to refer to each other as "father" and "son" (43). A similar vocabulary is used when Pete tattoos Phil: "Suddenly Pete Swallow became everything to me - wife, mother, father" (43). These passages envision tattooing and sex as activities that generate intimate relationships equal to those among family members. They thus offer a subversive rewriting of the glossary that is used to describe families and they place the privileged status that, in capitalist societies, is given to the family into question.

One productive framework for understanding Steward's text is J. Halberstam's idea of queer failure as a political and aesthetic concept. Halberstam's approach continues the narrative Love constructs about modernism, inasmuch as it traces the ramifications of the apparent incompatibility of queer desire with the narratives of progress that shape modernist aesthetics. Halberstam argues, in The Queer Art of Failure that, in contemporary capitalist societies "success" translates into "specific forms of reproductive maturity combined with wealth accumulation" (2). 
While Love suggests that modernist art associates queerness with "backwardness," Halberstam scrutinizes the logic that "casts the homosexual as inauthentic and unreal, as incapable of proper love and unable to make the appropriate connections between sociality, relationality, family, sex, desire, and consumption" (95). Love's concept of "backwardness" and Halberstam's ideas about "failure," in spite of the apparently negative connotations, are meant as concepts of resistance. Both interventions visualize the link between art and politics. They invite us to envision narratives that offer alternatives to hegemonic conceptualizations of progress and success, and function as sites of resistance.

One such site of resistance can be found in Steward's writing. The replacement of blood relationships by forms of kinship that are generated through tattooing and sex, in his story, challenges the heteronormative discourse Halberstam describes. It celebrates Phil and Pete's shared disregard for conventional values. Simultaneously, the parallel functioning of tattooing and gay sex forges strong links between both activities. These are affirmed by the fact that Phil uses sex as currency for paying for his new tattoo. The two men frame their intimacies as a "complex father-son relationship" (43) and as an economic transaction and thus explicitly refuse "to make the appropriate connections between sociality, relationality, family, sex, desire, and consumption." Their relationship exposes and subverts the capitalist logic. Family is not conceptualized as a sphere of continuity, reproduction, and assimilation but as a temporary arrangement that is based on sexual attraction, shared experience, and Pete's ability to pay for Phil's company.

Steward's story, in consonance with its questioning of the hierarchies that are imposed by heteronormativity, also unsettles ekphrastic, and therefore aesthetic, traditions. Phil's tattoo is a reference to queer sexuality. It thus rejects the traditional gendering of image and texts and the notion of romance that goes with it. The tattoo is described in detail in the dialogues between Pete and Phil, a strategy that confirms Glavey's idea that "Ekphrasis is not simply about seeing; it is also about showing and sharing" (6). The tattoo shows a "dickybird," a whip, and a rose (39). These signs are subversive, not only because they openly allude to socially ostracized sexual practices, but, conversely, also because they resist interpretation. Pete calms Phil's anxieties about being identified as homosexual through the tattoo, by joking that policemen will take the image of the "dickybird" for an "Air 
Force design" (39). He also recommends that Phil should reply to inquiries about the meaning of the other components of the tattoo by explaining that he "used to know girl named Rose who liked to be whipped" (40). The mistranslations of the images into words accentuate the duplicity of the tattoo. While it denotes Phil's erotic tastes, it can also camouflage as an arbitrary and meaningless sign. Ekphrasis, in Steward's story, is not only descriptive but also lays bare the deceptive character of words that seek to envelope an image.

The joke about the rose is particularly noteworthy because, according to Pete's interpretation, it is meant to represent Phil's "soft center" (40). Readers who are acquainted with Steward's constant allusions to Gertrude Stein and Alice B. Toklas may speculate that the rose encodes yet another meaning and can be read as a reference to Stein's poetry. This possibility seems particularly significant if we consider that the rose is meant as a symbol of vulnerability. Yet, the intimate reference is hidden behind a joke about "girl named Rose" and her masochistic desires. Beeler observes that "Despite its permanence, the tattoo may also resist images of stability and suggest the possibility of re-invention and re-interpretation" (6). The statement illuminates Steward's use of ekphrasis. The description of Phil's tattoo rejects accuracy and reliability and instead embraces playfulness, sensuality, and humor. Pete and Phil's relationship similarly eludes legibility. It is not only characterized by homoerotic attraction; the encounters between two characters that are both modeled on Steward himself also evoke masturbation and narcissism. These connotations are strengthened by the fact that Steward's story openly deals with experiences of aging, isolation, and, as the Wordsworth citation in the first sentence of the story anticipates, loneliness. Pete and Phil's "complex father-son relationship" only offers temporary solace. In consonance with Glavey's idea that queer ekphrasis "maintains an openness to failure" (4), in Steward's story the liberating energies of failure are used to challenge heteronormative views on sexuality.

While the incongruities between Steward's various spheres of identification ultimately remain unresolved in Bad Boys and Tough Tattoos and Below the Belt, there is also a text in which Steward offers a solution to this tension. In the brief memoir in the volume Dear Sammy (1977) that collects the letters Stein and Toklas wrote to him, Steward presents a scene in which he confesses to Alice his change to tattooing after Gertrude's death. Alice offers the following response: “The whole 
thing is wonderful [...] I do wish Gertrude could have heard of this" (103). The fantasy of Stein's approval is certainly significant. Steward once again rewrites modernist traditions in order to mitigate the distance between tattooing and the world of the literary avant-garde of which he once craved to become a part of.

\section{Sylvia Plath: Tattooing and Queer Fantasy}

While tattooing became an art that permanently changed Steward's life, Sylvia Plath's experiences with this medium were limited to one visit to a tattoo shop in Boston in 1958. This visit appears to be only a footnote in her life, and left no marks on her body, but Plath's journal allocates considerable space to the experience and she also composed her short story "The Fifteen-Dollar Eagle" (1959) based on it. Plath's interest in tattooing corresponds to her fascination with other visual formats that are located outside the spheres of high art. Julia Gordon-Bramer shows, in Fixed Stars Govern a Life, that Plath's Ariel poems are significantly influenced by the symbolic system of the tarot. Plath's affinity to visual traditions that elude academic tastes also becomes graspable in the response to the tattoo shop she formulates in her journal: "Much happier today - why? Life begins minutely to take care of itself - an odd impulse brings a flood of joy, life - queer nice slightly sinister people: at the tattooist" (422).

From Plath's journal, we learn that, in the weeks preceding her visit to the tattoo shop, she was concerned with combining her artistic ambitions with her domestic ambitions. She mentions her desire for "a corner of my own, something I can know about, write about well" (405) but also the "queer growing hunger for a baby" (411). While Plath's craving for a domestic scenario with children and a home corresponds to a conventional narrative of success - "reproductive maturity and wealth accumulation" - Plath also cultivates hopes that, in her eyes, are not that easily compatible with the conformist narrative: "I have my own dream, which is mine \& not the American dream. I want to write funny \& tender women's stories. I must be also, funny \& tender" (412). Andrea Krafft suggests that Plath's plan to use "humor and tenderness" in her prose makes up part of a feminist agenda that seeks "to unite" 
readers "in a common affective bond" in order to create a "female community" (287). This project is noteworthy in the context of a queer reading of Plath, as in another journal entry, "tenderness" is a word Plath associates with lesbian relationships: "what does a woman see in another woman that she doesn't see in a man: tenderness" (460). Plath recycles these words in The Bell Jar, in a conversation between the protagonist Esther and her psychiatrist (231). This repetition suggests that Plath found the idea of tenderness between women significant. The artistic ambition "to write funny \& tender women's stories "could, in the light of this passage, be understood as an ambition that is not entirely devoid of queer desire.

The scholarship on Plath has already established a good basis for queer readings. Plath's pronounced interest in lesbian relationships becomes apparent in The Bell Jar. Ricky Werner explores the protagonist Esther's concern with homosexuality and views it as indicative of the sexual crisis Esther goes through. According to this reading, Esther "aggressively pursues her heterosexual initiation" in order to free herself of homosexual impulses (8). While Esther rejects queer desires, Plath's novel nevertheless dwells on lesbian lifestyles as an alternative to the repressive norms that regulated heterosexual relationships in the 1950s. Werner astutely notes that the novel introduces "the character Joan Gilling as a double for its protagonist" and relegates queer desire to her: "Esther Greenwood is not a homosexual, but her double is" (5). This reading draws attention to the queer subtext of The Bell Jar and insinuates that the protagonist's dismissal of homosexuality is an act of self-denial: "When the mirror that is homosexuality is held up, Esther does not like what she sees" (8). The inability to acknowledge queer desire recalls Love's description of the marginalization of homosexuality in modernist literature: Esther perceives these desires as shameful and refuses to pursue them. The strategic use of a double, in Plath's novel, however, encourages readers to take the queer subtext seriously.

Plath also concerns herself with the repression of homosexual identities in the poem "The Courage of Shutting-Up" (1962). Critical commentaries that seek to read the poem in terms of autobiographical references, usually view it as a reaction to Plath's discovery of her husband's infidelity. Gordon-Bramer, however, argues that the poem is much more than a personal expression of rage. She suggests that one of the themes Plath works into the poem is the persecution of homosexuals during McCarthyism. The perspective of a wounded heterosexual woman and the 
perspective of gay men facing social ostracization overlap: "Plath must hold her tongue, like her homosexual friends in public" (200). Given that the poem explores mechanisms of silencing and introduces a scenario of surveillance ("Mirrors can kill and talk") this reading is plausible. Gordon-Bramer also associates the poem with the last tarot card of the major arcana, The World. She explains: "the card's figure is considered by many tarot scholars to be a hermaphrodite" (194). This reference also supports readings of the poem that link it to queer desire and ambiguous gender performance.

Interestingly, this poem also entails an ekphrastic evocation of tattooing: "Tattooing over and over the same blue grievances, / the snakes, the babies, the tits / on mermaids and two-legged dreamgirls." This flood of images confronts the observer with heterosexual norms: there are "dreamgirls" and "babies"; female bodies are exposed to the male gaze. Not surprisingly, the sequence of images is described as monotonous and depressing: an endless repetition of "the same blue grievances." It is noteworthy that the collection also includes tattoos that fail to fit into the heterosexual canon. There are mermaids, chimerical figures with a slippery identity, and snakes, symbols of seduction and transgression. These figures add a certain ambiguity to the scenario and hint at the possibility of escaping the heterosexual routine. Tattooing, then, constitutes a cultural practice that, for the speaker, is associated with ambiguous feelings. While tattooing makes use of visual codes that reproduce a conventional understanding of gender and of sexuality, it also has the potential to create more disruptive images.

A similar ambiguity towards tattooing also manifests itself in the short story "The Fifteen-Dollar Eagle." The story can be read as one of the "funny $\&$ tender women's stories", Plath envisions in her journals. An unnamed female narrator recounts her visit to a tattoo shop. Numerous coincidences with Plath's journals suggest the narrative is constructed in close vicinity to Plath's own experience. The narrator of the story negotiates ambivalent feelings towards the environment of the tattoo shop: admiration and the fantasy of forging a personal connection to the space alternate with a derisive attitude and the urge to mock the manner in which tattooing imitates other arts, such as poetry and painting, but fails to live up to them. Carmey, the tattoo artist in the story is introduced with the following words: "He's a real poet with the needle and dye, an artist with a heart" (47). The search for poetry in a tattoo shop 
indicates a craving for a form of poetry that is able to connote pain, to document suffering and to transport meaning through images. The analogy between poet and tattoo artist is plausible if we compare this catalogue with the ideals of authenticity and immediacy that are often associated with modernist poetry. In the course of her observations, Plath's narrator however experiences a process of disenchantment; she soon realizes that tattooing remains unable to fulfill its promises.

The narrative repeatedly returns to associations of tattooing with patriotic motifs and with marketing. The title of the story, "The Fifteen-Dollar Eagle," aptly conveys both aspects. The remark of another observer to the tattooist, "I believe you live on Uncle Sam's eagles," (53) cements the relationship of tattooing with national pride. The necessity to critically review the initial enthusiasm also derives from the perception that the space of the tattoo shop is closely linked to male self-performance. A sailor's decision to get tattooed is met with "admiration" and approval from the other male spectators in the shop (52). Female bodies, in this space, are turned into objects of voyeurism. The flash on the wall includes varieties of "red-nippled ladies" (54) and Carmey discloses his fantasy to tattoo the wings of a butterfly on a woman's thighs: "I'd like a photograph of that so much I'd practically do a butterfly for free" (60). The narrator's brief consideration of this proposition reinforces the link between tattooing and consumerism: "I toy, for a second, with the thought of a New Guinea Golden, wings extending from hipbone to kneecap [...] but drop it fast. A fine thing if I got tired of my own skin sooner than last year's sack" (60). The narrative thus exposes that the tattoo shop, in spite of its promise to provide a space in which conventional aesthetic ideals and hierarchies can be questioned, is inscribed with conservative values. It is revealed to be a sphere of patriotism, sexism, and the commercialization of desire. If we return to the initial analogy between tattoo artist and poet, we may speculate that the disenchantment with tattooing also represents a critical stance toward poetic traditions. Poetry, too, is a social practice that is susceptible to the influences of capitalism, patriotism, and machismo.

Beyond a research into the significance of tattooing as an art form, Plath's story, on a more hidden level, uses tattooing as a foil for testing, on the one hand her incompatible desires for domesticity, on the one hand, and non-conformist lifestyles, on the other. While Steward's writing constructs parallels between tattooing and sex, Plath's 
text compares tattooing to birth: "the finished eagle poises on a red sky, born and baptized in the blood of its owner" (56). Here, the act of creating a tattoo is envisioned as the act of procreation. The result is a monstrous form of birth, as the baby is not human but a beast, and it cannot live independently from its "owner." The incongruous elements in Plath's metaphors underline the impression that tattooing is an illegitimate, perhaps even deceitful art form that cannot fulfill its promise of authenticity and leads to false constructions of art and of parenthood. Plath's metaphors resemble Steward's evocation of masturbation, as here too tattooing, is a described as a sexualized act that fails to establish community and continuity. In contrast to the perversion of parenthood that is associated with tattooing, the narrator's own position is described through metaphors from a more conventional repertoire: "I settle on the crate of papers in the corner $[\ldots]$ careful as a hen on eggs" (52). The idea of the narrator as a "hen on eggs" consolidates her position in a conformist framework.

Plath's construction of tattooing as a failed form of art uses rhetoric strategies that resemble the ones queer theorists associate with the hegemonic discourse on sexuality: compared to the model of "reproductive maturity," queer relationships are constructed as "inauthentic," "incapable," and "inappropriate," to use Halberstam's terms. Compared to real art, tattooing is constructed as inauthentic and incapable in Plath's story. Interestingly, however, the story contains its own little queer fantasy. After the narrator learns that the tattoo artist has a wife, she immediately starts to daydream about Laura, the "Tattooed Lady" (51). When it turns out that Laura is not tattooed at all, and even detests tattoos, the narrator reviews the hopes she had harbored:

Up to this moment I have been projecting, fatuously, intimate visits with Laura [...]. I have been imagining a lithe, supple Laura, a butterfly poised for flight on each breast, roses blooming on her buttocks, [...] a woman with Experience written all over her, a woman to learn from in this life. (61)

Similar to the tattoo in Steward's narrative, the tattoos on Laura's body are a code for something else. For the narrator, the images translate into "Experience" and thus constitute a source of attraction. In her imagination, Laura becomes someone who inspires desires for intimacy. The obsession with Laura’s tattooed skin, including her breasts and buttocks, suggests that the relationship between both women, if follow- 
ing the script the narrator imagines, would entail an erotic dimension. The narrator's disappointment after meeting the "real" Laura is formulated in a manner that dissembles empathy with Laura's husband: "I imagine her body. Death-lily-white and totally bare -the body of a woman immune as a nun to the eagle's anger, the desire of the rose" (62). The erotic disenchantment, in spite of the show of sympathy for Carmey, seems to appertain to the narrator herself rather than anyone else. Plath's use of ekphrasis is deeply entwined with this sense of disappointment: her text conjures up seductive images of female sexuality, images with the "power to fix, excite, amaze, entrance, disturb" (Heffernan 7). However, these images are destined to remain a fantasy. For Plath's narrator, the visit to the tattoo shop thus turns into an experience of failure: tattooing, for her, does not offer a solution to the conflicts of identification she experiences. Plath's story returns to the conformist social order, after it has been revealed that the tattoo shop cannot hold its promises and does not provide a suitable space for artistic or erotic transgressions. Tattooing is disparaged as an inauthentic art; and the narrator and her boyfriend leave the shop apparently unmarked. Glavey's remark that queer ekphrasis "maintains an openness to failure" (4) is helpful in the context of Plath's story. Plath's narrator may entertain only a short-lived fascination with tattooing and remain oblivious of the queer subtext of her own thoughts. Similar to the repression of homosexuality in The Bell Jar and the strategy of relegating same-sex desire to an alter ego, this story is not devoid of homoerotic desire - the protagonist only fails to acknowledge her craving for new relationship models that unsettle the heteronormative logic.

\section{Conclusion: Aesthetics of Queer Failure}

Why is tattooing such an apt medium for expressing unease or dissatisfaction with heteronormativity, and how can it be employed in order to challenge cemented aesthetic ideals? Beeler suggests the following about literary texts that evoke tattooing through ekphrastic description: "One of the striking features of the textual tattoo is its ability to generate narratives of desire and violence because of the relationship between tattoos and the body" (4). In a similar vein, I have argued 
that references to tattooing in writing are often tied to a questioning of the social and aesthetic norms around which narratives about romance and sexuality are organized. Both Steward and Plath write in the context of cultural environments where tattooing is marginalized as a form of art. Perhaps it is this cultural location of tattooing on the lower end of the aesthetic hierarchy that allows both writers to associate tattooing with the promise of fulfilling queer desires; desires, which acclaimed art in the era of the 1950 os fails to respond to.

The marginalization of queer desire leads Steward and the protagonists of his fiction into realms that are constructed as "inauthentic" in the hegemonic discourse. Steward's appropriation of tattooing and pornography for queer aesthetics and queer relationships allows him to become a writer and creator who bypasses conventional patterns of success. Moreover, he exposes the hierarchies that structure these conventional narratives. Plath, by contrast, offers a female perspective on the tattoo culture of the 1950s. Her story contains elements that permit us to read it as one of the "funny \& tender women's stories" she envisions in her journals. The exposure of the tattoo shop as a space of masculine self-performance and conventional aesthetic ideals is certainly humorous. The narrator's daydream about a female confidante, a friend, whose tattooed body connotes "Experience" and female desire, reads as a counter vision to heteronormative models for relationships. This fantasy of tenderness between women introduces a new dimension into the world of tattooing and suggests that the visit to the tattoo shop, in spite of the narrator's disenchantment, is an incisive experience after all.

The engagement of both writers with tattooing can be productively read through a perspective that is informed by Love's observations about the repression of queer desire in modernist literature and by Halberstam's concept of queer failure as a form of resistance against the capitalist logic. The stories Plath and Steward create about tattooing critically reflect modernist traditions of writing. Steward's repeated references to Gertrude Stein offer him the possibility to link his own oeuvre to modernism, thereby tying tattooing and queer sexuality to a canon that tends to eclipse these practices. Plath's story explores the scope of modernist aesthetics by constructing analogies between the tattoo artist and a poet. This strategy enables her to dissociate herself from literary traditions that are shaped by masculine self-performance and patriotism. Moreover, both writers cultivate an awareness of the manner in which 
capitalism privileges narratives of financial and reproductive success. Steward responds to the demands of a heteronormative system by exploring cultural niches that elude institutionalization. For him, tattooing and pornography are spheres of resistance. These genres allow him to voice queer desire and to envision narratives that deliberately fail to comply with modernist standards. In her journals, Plath similarly voices the desire for "a corner of my own." Her short story depicts a woman in search for such a corner: the tattoo shop tempts her with the promise of non-conventional forms of artistic expression. Additionally, it is also associated with queer desire. While these promises remain fantasy, they momentarily destabilize the protagonist's position within the heteronormative system.

\section{Louisa Söllner}

(PhD, Ludwig-Maximilians-University Munich, 2012). She has published articles on Cuban-American literature and art and on the relationship between writing and visual art. Her book Photographic Ekphrasis in Cuban-American Fiction: Missing Pictures and Imagining Loss and Nostalgia was published by Brill (Leiden, NL) in August 2018.

\section{WORKS CITED}

Andros, Phil. "Note," Below the Belt \& Other Stories by Phil Andros. 2nd edition. San Francisco: Perineum Press, 1983, pp. ix-x.

Andros, Phil. "Love me little, love me long," Below the Belt \& Other Stories by Phil Andros. 2nd edition. San Francisco: Perineum Press, 1983, pp. 36-47.

Arburg, Hans-Georg von. "Archäodermatologie der Moderne. Zur Theoriegeschichte der Tätowierung in der Architektur und Literatur zwischen 1830 und 1930," Deutsche Vierteljahrsschrift für Literaturwissenschaft und Geistesgeschichte. 77.3 (2003): 407-445. 
Beeler, Karin. Tattoos, Desire and Violence: Marks of Resistance in Literature, Film and Television. Jefferson, North Carolina, and London: McFarland \& Company, 2005.

Brain, Tracy. The Other Sylvia Plath. London and New York: Routledge, 2001.

DeMello, Margo. Bodies of Inscription. A cultural history of the modern tattoo community. Durham, North Carolina: Duke University Press 2000.

Glavey, Brian. The Wallflower Avant-Garde: Modernism, Sexuality, and Queer Ekphrasis. New York and Oxford: Oxford University Press, 2016.

Gordon-Bramer, Julia. Fixed Stars Govern a Life: Decoding Sylvia Plath. Volume I: The Major Arcana and first 22 Poems of Plath's Ariel. Nacogdoches, Texas: Stephen F. Austin State University Press, 2014.

Halberstam, Judith. The Queer Art of Failure. Durham, North Carolina: Duke University Press, 2011.

Heffernan, James A.W. Museum of Words: The Poetics of Ekphrasis from Homer to Ashbery. Chicago and London: University of Chicago Press, 1993.

Krafft, Andrea. “'Funny and Tender and Not a Desperate Woman:' Sylvia Plath's The Bell Jar, Betty Friedan's The Feminine Mystique, and Therapeutic Laughter," Plath Profiles. An Interdisciplinary Journal for Sylvia Plath Studies 6 (2013): 287306.

Krieger, Murray. "The Problem of Ekphrasis: Image and Words, Space and Time - and the Literary Work," Pictures into Words: Theoretical and Descriptive Approaches to Ekphrasis, edited by Valerie Robillardand Els Jongeneel, Amsterdam: vU University Press, 1998, pp. 3-20.

Love, Heather. Feeling Backward. Loss and the Politics of Queer History. Cambridge, Massachusetts: Harvard University Press, 2007.

Muñoz, José Esteban. Disidentifications: Queers of Color and the Performance of Politics. Minneapolis and London: The University of Minnesota Press, 1999.

Plath, Sylvia: The Bell Jar. 2nd edition. London: Faber \& Faber, 1966. 
Plath, Sylvia. “The Courage of Shutting-Up," Collected Poems. London: Faber \& Faber, 1981, pp. 209-210.

Plath, Sylvia: “The Fifteen-Dollar Eagle," Johnny Panic and the Bible of Dreams and other prose writings. 2nd edition. London: Faber \& Faber, 1979, pp. 47-62.

Plath, Sylvia. The Unabridged Journals of Sylvia Plath 1950-1962, edited by Karen V. Kukil. New York: Anchor Books, 2000.

Spring, Justin. Secret Historian. The life and times of Samuel Steward, professor, tattoo artist, and sexual renegade. New York: Farrar Straus and Giroux, 2010.

Steward, Samuel. Bad Boys and Tough Tattoos: A Social History of the Tattoo with Gangs, Sailors and Street-Corner Punks, 1950-1965. New York and London: Harrington Park Press, 1990.

Steward, Samuel: “The Memoir," Dear Sammy. Letters from Gertrude Stein and Alice B. Toklas. New York: St. Martin's Press, 1977, pp. 1-117.

Werner, Ricky. "Queer Adolescence: (Homo)sexuality in The Catcher in the Rye and The Bell Jar," eSharp issue on Identity and Marginality 6.2 (Spring 2006). 